Military Technical College

Kobry El-Kobba

Cairo, Egypt

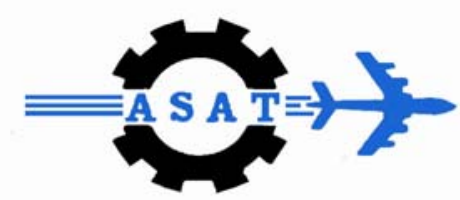

12-th International Conference on

Aerospace Sciences \& Aviation Technology

\title{
RANDOM RESPONSE OF SHAPE MEMORY ALLOY HYBRID COMPOSITE PLATES SUBJECT TO WHITE-GAUSSIAN NOISE AND THERMAL ENVIRONMENT
}

\author{
Ibrahim $^{*}$ H.H., Tawfik ${ }^{* \star}$ M., Negm ${ }^{* *}$ H.M
}

\begin{abstract}
The random response and thermal buckling of a traditional composite plate impregnated with pre-strained shape memory alloy (SMA) fibers subjected to combined thermal and acoustic loads are investigated using a finite element model based on the first order shear deformable plate theory and von Karman straindisplacement relations to account for moderately large deflection. The thermal load is assumed to be steady state constant temperature distribution, and the acoustic excitation is considered to be a stationary Gaussian pressure with zero mean and uniform magnitude over the plate surface. The governing nonlinear equations are obtained using the principal of virtual work adopting an approach based on the thermal strain being an integral quantity of the thermal expansion coefficient with respect to temperature to account for temperature dependent material properties. The static nonlinear equations are solved by Newton-Raphson numerical technique to get the thermal post-buckling deflection. The dynamic nonlinear equations of motion are transferred to modal coordinates to reduce the computational efforts. The Newmark implicit integration scheme is employed to solve the second order ordinary differential equations of motion. Finally, the buckling temperature, post-buckling deflection and the random response of a SMA hybrid composite plate panel are
\end{abstract}

\footnotetext{
${ }^{*}$ Research Assistant, Noon for Research and Development, noonrd.org \& National Authority for Remote Sensing and Space Sciences, Cairo, Egypt,_Hesham.ibrahim@noonrd.org.

${ }^{* *}$ Assistant Professor, Modeling and Simulation in Mechanics Department, German University in Cairo, Egypt, Mohammad.Tawfik@guc.edu.eg.

${ }^{\star \star *}$ Professor, Aerospace Engineering Department, Faculty of Engineering, Cairo University, Egypt Hmnegm_cu@hotmail.com.
} 
presented, illustrating the effect of SMA volume fraction, pre-strain, sound pressure level and temperature rise on the panel response.

\section{KEY WORDS}

Shape Memory Alloy, Nonlinear Random Response, Thermal buckling. 


\section{INTRODUCTION}

The external skin of high speed flight vehicles experiences high temperature rise due to aerodynamic heating, which can induce thermal buckling and dynamic instability. In general, thermal buckling does not indicate structural failure. However, thermal large deflection of the skin panels can change its aerodynamic shape causing reduction in the flight performance. A comprehensive literature review on thermally induced flexure, buckling, and vibration of plates and shells was presented by Tauchart [1] and Thornton [2]. Gray and Mei [3] investigated the thermal postbuckling behavior and free vibration of thermally buckled composite plates using the finite element method. Shi and Mei [4] solved the problem of thermal post-buckling of composite plates with initial imperfections using the finite element modal method. Jones and Mazumdar [5] investigated the linear and non-linear dynamic behavior of plates at elevated temperatures. They presented analytical solutions for the thermal buckling and post-buckling behavior of a plate strip. A general formula is also presented which links the fundamental frequency of vibration to the critical buckling temperature and the corresponding frequency of the unheated plate. Shi et al. [6] investigated the thermal post-buckling behavior of thin symmetrically laminated and anti-symmetric angle-ply plates, and the deflection of asymmetrically laminated composite plates under mechanical and thermal loads.

The Surface Panels of advanced high speed aircraft and spacecraft exhibit large random vibration under high acoustic loads, and possibly experience both of random vibration and thermal buckling at elevated temperatures. Both of these effects are nonlinear in nature, and make prediction of fatigue life extremely difficult. Experiments were performed to study thermally loaded panels under random excitation by Istenes et al.[7], $\mathrm{Ng}$ and Clevenson [8] and Murphy et al. [9]. Snapthrough phenomenon and frequency shifting due to nonlinear large amplitude vibration were observed. There are five major analysis methods for the prediction of nonlinear random response of panels: (a) perturbation, (b) Fokker-Plank-Kolmogorov (FPK equation), (c) Monte Carlo, (d) equivalent linearization (EL), and (e) finite element (FE) numerical integration. Perturbation method has been limited to very weak geometrically nonlinear problems, thus not suitable for the implementation of large nonlinear random vibration. FPK method can lead to exact solution only for single degree of freedom (DOF) systems. EL method has been widely used because of its high accuracy while maintaining a relatively low computational burden. The application of EL method depends on the assumption of Gaussian distribution of the response, thus it can not predict the occurrence of snap-through, since snap-through phenomenon has non-Gaussian distribution in nature. The finite element numerical integration approach actually combines the finite element and Monte Carlo simulation method. One disadvantage is the computational cost, because the finite element model often includes huge number of structural nodal DOF, and the nonlinear terms are updated and assembled at each time step and at each iteration cycle if an implicit numerical integration scheme is adopted. Locke [10] investigated the large deflection random vibration of a thermally buckled thin isotropic plate, using the method of equivalent linearization, while assuming a temperature-independent material properties. Abdel-Motagaly et al. [11] used finite element numerical integration to study nonlinear panel response under combined aerodynamic and acoustic loads. Dhainaut et al. [12] and [13] presented a finite element formulation for the prediction 
Shape memory alloys (SMAs) have a unique ability to completely recover large prestrains (up to 10\%) when heated above certain characteristic temperature called the austenite finish temperature. The austenite start temperature for Nitinol can be any where between $-50^{\circ} \mathrm{C}$ and $170^{\circ} \mathrm{C}$ by varying the nickel content. During the shape recovery process, a large tensile recovery stress occurs if the SMA is restrained. Cross et al. [15] measured the recovery stress of Nitinol at various pre-strain values and Young's modulus versus temperatures. Both the recovery stresses and Young's modules of SMA exhibit nonlinear temperature-dependent properties. The variation of the modulus of elasticity and recovery stress of a trained Nitinol is presented in Figs. 1 and 2 [15].

Birman [16] presented a comprehensive review on the literature concerning SMA up to 1997. Jia and Rogers [17] formulated a mechanical model for composites with embedded shape memory alloy fibers using the micromechanical behavior of the highly nonlinear shape memory alloy, and adopting the classical lamination plate theory. Park et al. [18] investigated the nonlinear vibration behavior of thermally buckled composite plates embedded with shape memory alloy fibers using the first order shear deformable plate theory and the von Karman strain-displacement relationships for large deflections. An incremental method was adopted to account for the temperature dependent material properties. Guo [19] offered an efficient finite element method for predicting the buckling temperature, post buckling deflection, and vibration characteristics of SMA hybrid composites. Tawfik et al. [20] proposed a novel concept in enhancing the thermal buckling and aeroelastic behavior of plates through embedding SMA fibers in it. Duan et al. [21] presented a finite element formulation and solution procedure for the vibration behavior of thin SMA hybrid arbitrary laminated composite plates. Gou et al. [22] developed a finite element procedure to predict large amplitude nonlinear random response of thin shape memory alloy hybrid composite plates subject to combined thermal load and acoustic excitation.

This paper is an extension of the work presented in [19] by including the shear deformation effect in the formulation to make it capable of handling moderately thick plates. In this work, a new nonlinear finite element model based on the first-order shear deformable plate theory is presented for the nonlinear random response and thermal buckling behavior of moderately thick shape memory alloy hybrid composite plate panels under the combined effect of thermal and acoustic loads are investigated using a nonlinear finite element method. The nonlinear governing equations for a moderately thick rectangular plate are obtained using the first-order shear-deformable plate theory (FSDT), von Karman strain-displacement relations, and the principle of virtual work. The approach is based on the thermal strain being an integral quantity of the thermal expansion coefficient with respect to temperature to account for temperature dependent material properties. Therefore, the method 


\section{FINITE ELEMENT FORMULATION}

\subsection{Displacement-Nodal Displacement Relations}

The nodal degrees of freedom vector of a nine-noded rectangular plate element can be written as:

$$
\{\delta\}=\left\{\left\{w_{b}\right\},\left\{\phi_{x}, \phi_{y}\right\},\{u, v\}\right\}^{T}=\left\{\begin{array}{l}
\left\{w_{b}\right\} \\
\left\{w_{\phi}\right\} \\
\left\{w_{m}\right\}
\end{array}\right\}
$$

where $w_{b}$ is the transverse displacement of the middle plane, $\phi_{x}$ and $\phi_{y}$ are rotations of the transverse normal about the $x$ and $y$ axes respectively, $u$ and $v$ are the membrane displacements in the $x$ and $y$ directions respectively, $\left\{w_{\phi}\right\}$ is the nodal rotation of the transverse normal vector, and $\left\{w_{m}\right\}$ is the nodal membrane displacement vector.

The displacement-nodal displacement relation can be presented in terms of interpolation function matrices $\left[N_{w}\right],\left[N_{\phi x}\right],\left[N_{\phi y}\right],\left[N_{u}\right]$ and $\left[N_{v}\right]$ as:

$$
\begin{gathered}
w=\left[N_{w}\right]\left\{w_{b}\right\}, \phi_{x}=\left\lfloor N_{\phi x}\right]\left\{w_{\phi}\right\}, \phi_{y}=\left\lfloor N_{\phi y}\right]\left\{w_{\phi}\right\}, \\
u=\left[N_{u}\right]\left\{w_{m}\right\} \text { and } v=\left[N_{v}\right]\left\{w_{m}\right\}
\end{gathered}
$$

\subsection{Nonlinear Strain-Displacement Relations}

The inplane strains and curvatures, based on von Karman's large deflection and firstorder shear deformable plate theory, are given by [24]:

$$
\left\{\begin{array}{c}
\varepsilon_{x} \\
\varepsilon_{y} \\
\gamma_{x y}
\end{array}\right\}=\left\{\begin{array}{c}
\frac{\partial u}{\partial x} \\
\frac{\partial v}{\partial y} \\
\frac{\partial u}{\partial y}+\frac{\partial v}{\partial x}
\end{array}\right\}+\left\{\begin{array}{c}
\frac{1}{2}\left(\frac{\partial w}{\partial x}\right)^{2} \\
\frac{1}{2}\left(\frac{\partial w}{\partial y}\right)^{2} \\
\frac{\partial w}{\partial x} \frac{\partial w}{\partial y}
\end{array}\right\}+z\left\{\begin{array}{c}
\frac{\partial \phi_{y}}{\partial x} \\
\frac{\partial \phi_{x}}{\partial y} \\
\frac{\partial \phi_{y}}{\partial y}+\frac{\partial \phi_{x}}{\partial x}
\end{array}\right\}
$$

Or in compact form

$$
\{\varepsilon\}=\left\{\varepsilon_{\text {lin }}\right\}+\left\{\varepsilon_{\theta}\right\}+z\{\kappa\}
$$


$\varepsilon_{\text {lin }}, \varepsilon_{\theta}$, and $z \kappa$ are the membrane linear strain vector, the membrane nonlinear strain vector, and the bending strain vector, respectively.

The transverse shear strain vector can be expressed as [24]:

$$
\left\{\begin{array}{l}
\gamma_{y z} \\
\gamma_{x z}
\end{array}\right\}=\left\{\begin{array}{l}
\phi_{x} \\
\phi_{y}
\end{array}\right\}+\left\{\begin{array}{l}
\frac{\partial w}{\partial y} \\
\frac{\partial w}{\partial x}
\end{array}\right\}
$$

\subsection{Constitutive Equations}

The constitutive equations of a traditional composite plate impregnated with shape memory alloy fibers are derived. Every layer of the composite matrix has an arbitrary orientation angle $\theta$ and principal material directions 1,2 and 3. The SMA fiber is embedded in the 1-direction, and assumed uniformly distributed within each layer.

where the subscripts ' $\mathrm{m}$ ' and 's' mean the composite matrix and SMA fiber, respectively. $E, G, v$, and $\rho$ are Young's modulus, the shear modulus, Poisson's ratio, and the material density, respectively. In addition,

For the $\mathrm{k}^{\text {th }}$ composite lamina impregnated with SMA fibers, the stress-strain relations for the FSDT can be expressed as follows [19]:

$$
\begin{aligned}
& \{\sigma\}^{k}=\left\{\begin{array}{c}
\sigma_{x} \\
\sigma_{y} \\
\tau_{x y}
\end{array}\right\}^{k}=[\bar{Q}(T)]^{k}\{\varepsilon\}+\left\{\sigma_{r}(T)\right\}^{k} V_{s}^{k}-[\bar{Q}(T)]_{m}^{k} V_{m}^{k} \int_{\text {Tref }}^{T}\left\{\alpha(\tau)_{m}^{k}\right\} d \tau \\
& \{\tau\}^{k}=\left\{\begin{array}{l}
\tau_{y z} \\
\tau_{x z}
\end{array}\right\}^{k}=\left[\begin{array}{ll}
\bar{Q}_{44}(T) & \bar{Q}_{45}(T) \\
\bar{Q}_{45}(T) & \bar{Q}_{55}(T)
\end{array}\right]\left\{\begin{array}{l}
\gamma_{y z} \\
\gamma_{x z}
\end{array}\right\}
\end{aligned}
$$

where $\{\sigma\},\left\{\sigma_{\mathrm{r}}\right\}$ and $\{\tau\}$ are the inplane stress vector, the SMA recovery stress vector at a given temperature $\mathrm{T}$, and the transverse shear vector, respectively. $V_{m}$ and $V_{s}$ are the volume fractions of the composite matrix and SMA fibers, respectively. In addition, $\{\alpha\}_{\mathrm{m}},[\bar{Q}]$ and $[\bar{Q}]_{\mathrm{m}}$ are the thermal expansion coefficient vector of the composite matrix, the transformed reduced stiffness matrix of the SMA embedded lamina, and the transformed reduced stiffness matrix of the composite matrix, respectively.

Integrating Equations (6) and (7) over the plate thickness, the constitutive equation is obtained as [19]:

$$
\left\{\begin{array}{l}
\{N\} \\
\{M\}
\end{array}\right\}=\left[\begin{array}{ll}
{[A]} & {[B]} \\
{[B]} & {[D]}
\end{array}\right]\left\{\begin{array}{c}
\left\{\varepsilon_{m}\right\} \\
\{\kappa\}
\end{array}\right\}-\left\{\begin{array}{l}
\left\{N^{T}\right\} \\
\left\{M^{T}\right\}
\end{array}\right\}+\left\{\begin{array}{l}
\left\{N_{r}\right\} \\
\left\{M_{r}\right\}
\end{array}\right\}
$$




$$
\{R\}=\left\{\begin{array}{l}
R_{y z} \\
R_{x z}
\end{array}\right\}=\left[\begin{array}{ll}
A_{44} & A_{45} \\
A_{45} & A_{55}
\end{array}\right]\left\{\begin{array}{l}
\gamma_{y z} \\
\gamma_{x z}
\end{array}\right\}=[A]^{s}\{\gamma\}
$$

where

$$
\begin{aligned}
& \left\{\varepsilon_{m}\right\}=\left\{\varepsilon_{\text {lin }}\right\}+\left\{\varepsilon_{\theta}\right\} \\
& \left(\left\{N^{T}\right\},\left\{M^{T}\right\}\right)=\int_{-h / 2}^{h / 2}\left[Q(T)\left(\int_{T_{r e f}}^{T} \alpha(\tau) d \tau\right)\right](1, z) d z \\
& \left(\left\{N_{r}\right\},\left\{M_{r}\right\}\right)=\int_{-h / 2}^{h / 2}\left\{\sigma_{r}\right\} V_{s}(1, z) d z
\end{aligned}
$$

where $[A],[A]^{\mathrm{s}},[B]$ and $[D]$ are the laminate membrane, shear, coupling and bending stiffness matrices, respectively. $\{N\},\{M\}$ and $\{R\}$ are the resultant vectors of the inplane, moment and transverse shear forces. In addition, $\left\{N^{T}\right\}$ and $\left\{M^{T}\right\}$ are the inplane thermal load and thermal bending moment vectors, respectively, while $\left\{N_{r}\right\}$ and $\left\{M_{r}\right\}$ are the inplane SMA recovery load and SMA recovery bending moment vectors. T denotes the temperature rise, while a constant temperature distribution in the $\mathrm{x}, \mathrm{y}$ and $\mathrm{z}$ directions are assumed.

\subsection{Governing Equations}

By using the principle of virtual work and equations (4), (5), (8) and (9), the governing equations of thermal post-buckling and nonlinear flutter limit-cycle oscillation of a plate embedded with SMA fibers can be derived as follows:

$$
\delta W=\delta W_{\mathrm{int}}-\delta W_{\text {ext }}=0
$$

The internal virtual work $\delta W_{\text {int }}$ is given as [20]:

$$
\begin{aligned}
\delta W_{\text {int }} & =\int_{A}\left(\left\{\delta \varepsilon_{m}\right\}^{T}\{N\}+\{\delta \kappa\}^{t}\{M\}+\beta\{\delta \gamma\}^{T}\{R\}\right) d A \\
& =\{\delta w\}^{T}\left([k]-\left[k_{T}\right]+\left[k_{r}\right]+\frac{1}{2}[n 1]+\frac{1}{3}[n 2]\right)\{w\}-\{\delta w\}^{T}\left(\left\{p_{T}\right\}-\left\{p_{r}\right\}\right)
\end{aligned}
$$

where $\{w\}$ is the nodal displacement vector of the element; $\beta$ is a shear correction coefficient; $[k],\left[k_{T}\right]$ and $\left[k_{r}\right]$ are the linear, thermal and recovery stress stiffness matrices; [n1] and [n2] are the first- and second-order nonlinear stiffness matrices, respectively. In addition, $\left\{p_{T}\right\}$ and $\left\{p_{r}\right\}$ are the thermal load vector and the recovery stress load vector, respectively.

On the other hand, the external virtual work $\delta W_{\text {ext }}$ is given as [18]: 


$$
\begin{aligned}
\delta W_{\text {ext }} & =\int_{A}\left(\begin{array}{l}
-I_{o}\left(\{\delta u\}^{T}\{\ddot{u}\}+\{\delta v\}^{T}\{\ddot{v}\}+\{\delta w\}^{T}\left\{\ddot{w}_{b}\right\}\right) \\
-I_{2}\left(\left\{\delta \phi_{x}\right\}^{T}\left\{\ddot{\phi}_{x}\right\}+\left\{\delta \phi_{y}\right\}^{T}\left\{\ddot{\phi}_{y}\right\}\right)+\left\{\delta w_{b}\right\}^{T} p(t)
\end{array}\right) d A \\
= & -\{\delta w\}^{T}[m]\{\ddot{w}\}+\left\{\delta w_{b}\right\}^{T} p(t)
\end{aligned}
$$

where $\left(I_{o}, I_{2}\right)=\int_{-h / 2}^{h / 2} \rho\left(1, z^{2}\right) d z$ with $h$ denoting the plate thickness, $[m]$ is the mass matrix, and $p(t)$ is a white Gaussian random pressure.

By substituting equations (11 and (12) into (10), the governing equations for a shape memory alloy hybrid composite plate under the combined action of acoustic and thermal loads, can be written as:

$$
[M]\{\ddot{W}\}+\left([K]-\left[K_{T}\right]+\left[K_{r}\right]+\frac{1}{2}[N 1]+\frac{1}{3}[N 2]\right)\{W\}=\{P(t)\}+\left\{P_{T}\right\}-\left\{P_{r}\right\}
$$

\section{SOLUTION PROCEDURES}

\subsection{Static thermal Buckling}

For the static thermal buckling problem, equation (13) reduces to:

$$
\left([K]-\left[K_{T}\right]+\left[K_{r}\right]+\frac{1}{2}[N 1]+\frac{1}{3}[N 2]\right)\{W\}=\left\{P_{T}\right\}-\left\{P_{r}\right\}
$$

The solution procedure using Newton-Raphson method for the aero-thermal postbuckling analysis of the composite plate embedded with SMA fibers is presented in the following.

Introducing the function $\{\Psi(W)\}$ to equation (14),

$$
\{\Psi(W)\}=\left([K]-\left[K_{T}\right]+\left[K_{r}\right]+\frac{1}{2}[N 1]+\frac{1}{3}[N 2]\right)\{W\}-\left\{P_{T}\right\}+\left\{P_{r}\right\}=0
$$

Equation (15) can be written in the form of a truncated Taylor series expansion as:

$$
\{\Psi(W+\delta W)\}=\{\Psi(W)\}+\frac{d\{\Psi(W)\}}{d(W)}\{\delta W\} \cong 0
$$

where [23] 


$$
\begin{aligned}
\frac{d\left\{\Psi\left(W_{s}\right)\right\}}{d\left(W_{s}\right)} & =\left([K]-\left[K_{T}\right]+\left[K_{r}\right]+[N 1]+[N 2]\right) \\
& =\left[\mathrm{K}_{\mathrm{tan}}\right]
\end{aligned}
$$

Thus, the Newton-Raphson iteration procedure for the determination of the postbuckling deflection can be expressed as follows:

$$
\begin{aligned}
& \left.\{\Psi(W)\}_{i}=\left([K]-\left[K_{T}\right]+\left[K_{r}\right]+\frac{1}{2}([N 1])_{i}+\frac{1}{3}([N 2])\right)_{i}\right)\{W\}-\left\{P_{T}\right\}+\left\{P_{r}\right\} \\
& {\left[K_{\text {tan }}\right]_{i}\{\delta W\}_{i+1}=-\{\Psi(W)\}_{i}} \\
& \{\delta W\}_{i+1}=-\left[K_{\text {tan }}\right]^{-1}\{\Psi(W)\}_{i} \\
& \{W\}_{i+1}=\{W\}_{i}+\{\delta W\}_{i+1}
\end{aligned}
$$

Convergence occurs in the above procedure when the maximum value of $\{\delta W\}_{i+1}$ becomes less than a given tolerance $\varepsilon_{t o l}$, i.e. $\max \left|\{\delta W\}_{i+1}\right| \leq \varepsilon_{t o l}$.

\subsection{Thermo-Acoustic Response using modal Transformation}

In this section, a time domain solution is presented for the nonlinear thermo-acoustic response of symmetrically laminated shape memory alloy hybrid composite plates. Equation (13) can be stated in a more detailed form as:

$$
\begin{aligned}
& {\left[\begin{array}{cc}
M_{B} & 0 \\
0 & 0
\end{array}\right]\left\{\begin{array}{l}
\ddot{W}_{B} \\
\ddot{W}_{m}
\end{array}\right\}+\left(\begin{array}{cc}
{\left[\begin{array}{cc}
K_{B} & 0 \\
0 & K_{m}
\end{array}\right]-\left[\begin{array}{cc}
K_{T B} & 0 \\
0 & 0
\end{array}\right]+\left[\begin{array}{cc}
K_{r B} & 0 \\
0 & 0
\end{array}\right]} \\
\left.+\frac{1}{2}\left[\begin{array}{cc}
N 1_{N m B} & N 1_{B m} \\
N 1_{m B} & 0
\end{array}\right]+\frac{1}{3}\left[\begin{array}{cc}
N 2_{B} & 0 \\
0 & 0
\end{array}\right]\right)\left\{\begin{array}{l}
W_{B} \\
W_{m}
\end{array}\right\}
\end{array}\right.} \\
& =\left\{\begin{array}{c}
P_{B}(t) \\
0
\end{array}\right\}+\left\{\begin{array}{c}
0 \\
P_{m T}
\end{array}\right\}-\left\{\begin{array}{c}
0 \\
P_{m r}
\end{array}\right\}=\left\{\begin{array}{c}
P_{B} \\
P_{m}
\end{array}\right\}
\end{aligned}
$$

where

$$
\left\{W_{B}\right\}=\left\{\begin{array}{l}
W_{b} \\
W_{\phi}
\end{array}\right\}
$$

Note that neglecting the in-plane and shear inertia terms will not bring significant error, because their natural frequencies are usually 2 to 3 orders of magnitude higher than those of bending [19]. Separating the membrane and transverse displacement equations in equation (18): 


$$
\begin{aligned}
& {\left[M_{B}\right]\left\{\ddot{W}_{B}\right\}+\left(\left[K_{B}\right]-\left[K_{T B}\right]+\left[K_{r B}\right]+\frac{1}{2}\left[N 1_{N m B}\right]+\frac{1}{3}\left[N 2_{B}\right]\right)\left\{W_{B}\right\}+\frac{1}{2}\left[N 1_{B m}\right]\left\{W_{m}\right\}=\left\{P_{B}\right\}} \\
& {\left[K_{m}\right]\left\{W_{m}\right\}+\frac{1}{2}\left[N 1_{m B}\right]\left\{W_{B}\right\}=\left\{P_{m}\right\}}
\end{aligned}
$$

From equation (20), the in-plane displacement vector $\left\{W_{m}\right\}$ can be expressed in terms of the bending displacement vector $\left\{W_{B}\right\}$ :

$$
\begin{aligned}
\left\{W_{m}\right\} & =\left[K_{m}\right]^{-1}\left\{P_{m}\right\}-\frac{1}{2}\left[K_{m}\right]^{-1}\left[N 1_{m B}\right]\left\{W_{B}\right\} \\
& =\left\{W_{m}\right\}_{o}-\left\{W_{m}\right\}_{2}
\end{aligned}
$$

where $\left\{W_{m}\right\}_{o}$ is a constant and $\left\{W_{m}\right\}_{2}$ is quadratically dependent on $\left\{W_{B}\right\}$. Thus, the matrix $\left[\mathrm{N} 1_{N m B}\left(\left\{W_{m}\right\}\right)\right]$ is evaluated by the algebraic sum of two components: $\left.\left[\mathrm{N} 1_{N m B}\left\{W_{m}\right\}_{o}\right)\right]$ and $\left.\left[\mathrm{N} 1_{N m B}\left\{W_{m}\right\}_{2}\right)\right]$, which are quadratically dependent on $\left\{W_{B}\right\}$, respectively.

Substituting equation (21) into (19), the system equations of motion can be expressed as a function of $\left\{W_{B}\right\}$ :

$$
\begin{aligned}
& {\left[M_{B}\right]\left\{\ddot{W}_{B}\right\}+\left(\left[K_{B}\right]-\left[K_{T B}\right]+\left[K_{r B}\right]+\left[N 1_{N m B}\left(\left\{W_{m}\right\}_{o}\right)\right]\right)\left\{W_{B}\right\}} \\
& +\left(\frac{1}{3}\left[N 2_{B}\right]-\frac{1}{2}\left[N 1_{N m B}\left(\left\{W_{m}\right\}_{2}\right)\right]-\frac{1}{4}\left[N 1_{B m}\right]\left[K_{m}\right]^{-1}\left[N 1_{m B}\right]\right)\left\{W_{B}\right\}=\left\{P_{B}\right\}
\end{aligned}
$$

For a given $\Delta T$, equation (22) can be numerically integrated in the structural nodal degrees of freedom. But this approach turns to be computationally expensive. Therefore, an alternative and effective solution procedure is to transform equation (32) into modal coordinates using reduced system normal modes by expressing the system bending displacement $\left\{W_{B}\right\}$ as a linear combination of a finite number of normal mode shapes as [22]:

$$
\left\{W_{B}\right\} \approx \sum_{r=1}^{n} q_{r}\left\{\phi_{r}\right\}=\left[\Phi_{B}\right]\{q\}
$$

where the $\mathrm{r}^{\text {th }}$ normal mode $\left\{\phi_{r}\right\}$ and the corresponding natural frequency $\omega_{r}$ are obtained from the linear vibration of the system as:

$\omega_{r}^{2}\left[M_{B}\right]\left\{\phi_{r}\right\}=\left[K_{B}\right]\left\{\phi_{r}\right\}$

Based on the normal modes evaluated in equation (24), all the matrices in equation (22) are transformed into modal coordinates; accordingly, equation (22) can be written in modal coordinates as:

$$
\left[\bar{M}_{B}\right]\{\ddot{q}\}+2\left[\zeta_{r} f_{r}\right]\left[\bar{M}_{B}\right]\{\dot{q}\}+\left([\bar{K}]+\left[\bar{K}_{q q}\right]\right)\{q\}=\left\{P_{B}\right\}
$$

where the modal mass, linear stiffness and random pressure matrices are given by: 


$$
\begin{aligned}
& \left(\left[\bar{M}_{B}\right],[\bar{K}]\right)=\left[\Phi_{B}\right]^{T}\left(\left[M_{B}\right],\left[K_{\text {lin }}\right]\right)\left[\Phi_{B}\right], \\
& {\left[K_{\text {lin }}\right]=\left[K_{B}\right]-\left[K_{T B}\right]+\left[K_{r B}\right]+\left[N 1_{N m B}\left(\left\{W_{m}\right\}_{o}\right)\right],}
\end{aligned}
$$

and

$$
\left\{\bar{P}_{B t}\right\}=\left[\Phi_{B}\right]^{T}\left\{P_{B t}\right\}=\left[\Phi_{B}\right]^{T}\left\{\begin{array}{c}
P_{b t} \\
0
\end{array}\right\}
$$

The second-order nonlinear modal stiffness matrix is given by:

$$
\left[\bar{K}_{q q}\right]=\left[\Phi_{B}\right]^{T} \sum_{r=1}^{n} \sum_{s=1}^{n} q_{r} q_{s}\left(\begin{array}{l}
\frac{1}{3}\left[N 2_{B}\right]^{(r s)}-\frac{1}{2}\left[N 1_{N m B}\left(\left\{W_{m}\right\}_{2}\right)\right]^{(r s)} \\
-\frac{1}{4}\left[N 1_{B m}\right]^{(r)}\left[K_{m}\right]^{-1}\left[N 1_{m B}\right]^{(s)}
\end{array}\right)\left[\Phi_{B}\right]
$$

A modal structural damping matrix $2\left[\zeta_{r} f_{r}\right]\left[M_{B}\right]$ has been added to equation (25) to account for the structural damping effect on the system. The coefficient $\zeta_{r}$ is the modal damping ratio of the $\mathrm{r}^{\text {th }}$ mode, while $f_{r}$ is the $\mathrm{r}^{\text {th }}$ natural frequency in $\mathrm{Hz}$.

\section{NUMERICAL RESULTS AND DISCUSSIONS}

Numerical analyses for the thermal post-buckling and the nonlinear acoustic random vibration of a laminated composite plate panel with and without SMA are performed using the finite element method. A uniform $6 \times 6$ finite element mesh of nine-noded rectangular elements is found adequate.

\subsection{Thermal Buckling Analysis}

The thermal post-buckling behavior of a traditional laminated composite plate with and without SMA is studied. The dimensions of the plate are $0.381 \times 0.305 \times 0.0013 m$ and the stacking sequence is $[0 /-45 / 45 / 90]_{s}$. Clamped and simply supported boundary conditions are studied. Table 1 presents the material properties of the composite matrix and SMA fibers [19]. A uniform temperature change is applied to the plate, and the reference temperature is assumed to be $21^{\circ} \mathrm{C}$.

Figs. 3 and 4 present the postbuckling deflection for three different pre-strains of SMA fibers with volume fraction $5 \%$, for simply supported and clamped plates, respectively. Comparing the buckling temperatures of the SMAHC plate with that of a composite plate with the same in-plane dimensions and weight, it is found that the buckling temperature for a simply supported SMAHC plate, seen in Fig. 3, is increased by $143 \%, 265 \%$, and $465 \%$ for $1 \%, 3 \%$, and $5 \%$ pre-strains, respectively. It is also seen that the $5 \%$ pre-strain case has two buckling temperatures. This is because for the temperature range from 21 to $43^{\circ} \mathrm{C}$, the $5 \%$ pre-stain curve, shown in 
Fig. 2, has a slower rate of recovery-stress increase with temperature than that of the $1 \%$ and $3 \%$ pre-strains, which makes the thermal stress dominates the SMA recovery stress during this temperature range, and hence, the plate experiences thermal buckling. But for temperatures above $43^{\circ} \mathrm{C}$, the $5 \%$ pre-stain curve has a higher rate of increase than those of temperatures lower than $43^{\circ} \mathrm{C}$, which causes the recovery stress to dominate the thermal stress to make the plate goes flat again at $72^{\circ} \mathrm{C}$, before reaching the second thermal buckling point at $86^{\circ} \mathrm{C}$. That is why the performance of the $5 \%$ pre-strain is always lower than that of the $1 \%$ and $3 \%$ values in the temperature range from 21 to $43^{\circ} \mathrm{C}$, i.e., from room temperature up to a temperature increase of $22^{\circ} \mathrm{C}$. For the clamped SMAHC, seen in Fig. 4 , it is found that the buckling temperature, relative to an equivalent weight composite plate, is increased by $54 \%, 109 \%$, and $175 \%$ for $1 \%, 3 \%$, and $5 \%$ pre-strains, respectively.

\subsection{Panel Response Under Combined Thermal and Random Acoustic Loads}

The plate nonlinear random vibration behavior is investigated with two parameters in the study: temperature rise $(\Delta T)$ and sound pressure level $(S P L)$; where $\Delta T$ varies from $0-150^{\circ} \mathrm{C}$, and $S P L$ from $90-130 \mathrm{~dB}$. The plate is modeled using a $6 \times 6$ mesh, or 36 nine-noded rectangular elements. A traditional clamped composite plate and a SMAHC plate with $5 \%$ volume fraction and $3 \%$ pre-strain are studied and compared. A proportional damping ratio of $\zeta_{r} f_{r}=\zeta_{s} f_{s}$ is used with a fundamental modal damping coefficient $\zeta_{1}$ equal to 0.02 . Newmark implicit numerical integration scheme [25] is utilized to solve the system differential equations with a time step of $1 / 10000 \mathrm{sec}$., while Newton-Raphson iteration scheme is adopted to solve the nonlinear algebraic system of equations at each time step. Six normal modes were found giving converged root mean square (r. m. s.) deflection and thus used. In order to eliminate the effect of initial transient response, the first $0.1 \mathrm{sec}$ out of a total period of $1 \mathrm{sec}$ time history is excluded from the statistical process.

Fig. 5 presents the time history response of a clamped traditional composite plate at $S P L=90 \mathrm{~dB}$ and temperature rises $0,50,100$, and $150{ }^{\circ} \mathrm{C}$. It seen that, at room temperature, the plate exhibits basically small deflection (r. m. s. $=0.0744)$ random vibration. At temperature rises 50,100 and $150{ }^{\circ} \mathrm{C}$, which are beyond the critical buckling temperature of the plate $\left(T_{c r}=22.5^{\circ} \mathrm{C}\right)$, the plate experiences small random vibration about the buckling equilibrium position with $\left(W_{\max } / h\right) 1.22,-2.12$, and 2.72 , respectively. It is also noticed that the vibration amplitude decreases as temperature increases beyond $T_{c r}$, because nonlinear stiffness terms add stiffness to the plate as thermal deflection increases. Fig. 6 presents the time history response of a clamped SMAHC plate at $S P L=90 \mathrm{~dB}$ and temperature rises $0,50,100$, and $150{ }^{\circ} \mathrm{C}$. It seen that at room temperature, the plate randomly vibrates with a small deflection $\mathrm{r}$. $\mathrm{m}$. $\mathrm{s}$. $=0.0825$, which is a little bit higher than that of the traditional composite plate due to the higher weight of the SMAHC plate while the SMA fibers being not activated yet. At temperature rise 50, the activation of SMA fibers results in lower vibration amplitudes and deflection r. m. s. values than that of the traditional composite plate presented in Fig. 5. At temperature rise $50{ }^{\circ} \mathrm{C}$, the thermal compressive stress dominates the SMA recovery stress results in a higher vibration amplitudes and deflection r. m. s. values than the 0 and $50{ }^{\circ} \mathrm{C}$ temperature rises. At temperature rise $150{ }^{\circ} \mathrm{C}$, which is beyond the critical buckling temperature of the SMAHC plate 
$\left(\Delta T_{c r}=136^{\circ} \mathrm{C}\right)$, the plate is seen to exhibit small vibration about one of the equilibrium buckling positions, $W_{\max } / h=0.68$, showing a strong snap-through phenomena between both of the buckling equilibrium positions.

Fig. 7 presents the time history response of a clamped traditional composite plate at $S P L=110 \mathrm{~dB}$. It seen that at room temperature, the plate randomly vibrates with deflection r. m. s. $=0.727$, which is much higher than that of the $90 \mathrm{~dB}$ case. At temperature rise $50{ }^{\circ} \mathrm{C}$, the plate shows very clear snap-through between the two buckling equilibrium positions, \pm 1.22 . At temperature rises 100 and $150{ }^{\circ} \mathrm{C}$, the occurrence of snap-through is resisted by the stiffness added by the increased thermal postbuckling deflection resulting in completely hindering snap-through motions and the plate shows moderate deflection r. m. s. random vibration about the buckling equilibrium positions $W_{\max } / h=-2.12$ and 2.72 , respectively. For the clamped SMAHC plate, presented in Fig. 8 , it is seen that the plate exhibits moderate deflection random vibration for the temperature rises 0,50 , and $100{ }^{\circ} \mathrm{C}$. At temperature rise $150{ }^{\circ} \mathrm{C}$, it is seen that the plate experiences a persistent snapthrough which covers both buckling equilibrium positions. It is also observed that the plate has a lower r. m. s. deflection at $50^{\circ} \mathrm{C}$ temperature rise than that of the $100^{\circ} \mathrm{C}$, because the recovery stress dominates the thermal expansion in the vicinity of the 50 ${ }^{\circ} \mathrm{C}$ temperature rise.

For the case of $130 \mathrm{~dB}$ sound pressure level at different values of temperature rise, shown in Figs. 9 and 10, both traditional composite and SMAHC plates show large amplitude nonlinear random vibrations covering both postbuckling equilibrium positions with a small reduction in the $\mathrm{r}$. $\mathrm{m}$. s. deflection. It is also observed that the occurrence of the intermittent snap-through motions is completely hindered as the nonlinear acoustic random vibration completely dominates the thermal expansion effect at high sound pressure levels.

\section{CONCLUSIONS}

In this work, a traditional composite plate impregnated with pre-strained shape memory alloy fibers and subject to combined thermal and acoustic loads, is investigated, to demonstrate the effectiveness of using SMA fiber embeddings in improving the static and dynamic response of composite plates. A new nonlinear finite element model for moderately thick plates using the first-order shear deformable plate theory is presented. von Karman strain displacement relations are utilized to account for geometric nonlinearity. The governing equations are obtained using the principle of virtual work. The nonlinear temperature dependence of material properties for the composite matrix and SMA fibers is considered in the formulation. Newton-Raphson iteration is employed to obtain the static thermal large deflection at each temperature step, and the dynamic response at each time step of the Newmark numerical integration scheme. The finite element modal formulation and solution procedures are developed for the time domain method. Results showed that SMA fiber embeddings can be very useful in thermal buckling through increasing the buckling temperature and decreasing or suppressing the thermal postbuckling deflections. It is also found that the response of the SMAHC plates is not favorable at low and medium sound pressure levels regarding fatigue life performance since they 
have higher vibration amplitudes than that of the traditional composite plates. While at high sound pressure levels, the SMA fiber embeddings have no pronounced effect on the response since the acoustic excitation completely dominates the thermal and the recovery stresses.

\section{REFERENCES}

[1] Tauchart, T.R., "Thermally Induced Flexure, Buckling, And Vibration Of Plates", Appl. Mech. Rev., Vol. 44, (1991).

[2] Thornton, E.A., "Thermal Buckling Of Plates And Shells", Appl. Mech. Rev., Vol. 46, pp 485-506, (1993).

[3] Gray, C.C. and Mei, C., "Finite Element Analysis Of Thermal Post-Buckling And Vibrations Of Thermally Buckled Composite Plates", AIAA J., 1239-CP, pp 29963007, (1991).

[4] Shi, Y. and Mei, C., "Thermal Post Buckling Of Composite Plates Using The Finite Element Modal Coordinate Method", AIAA J., 1467-CP, pp. 1355-1362, (1999).

[5] Jones, R. and Mazumdar, J., "Vibration And Buckling Of Plates At Elevated Temperatures", J. Solid Structures, Vol.16, pp. 61-70, (1980).

[6] Shi, Y., Lee, R.Y. and Mei, C., "Coexiting Thermal Post-Buckling Of Composite Plates With Initial Imperfections Using Finite Element Modal Method", J. Thermal Stresses, Vol. 22, pp. 595-614, (1999).

[7] Istenes, R.R., Rizzi, S.A. and Wolfe, H.F., "Experimental Nonlinear Random Vibration Results of Thermally Buckled Composite Panels", Proceedings of $36^{\text {th }}$ Structures, Structural Dynamics and Materials Conference, New Orleans, LA, pp. 1559-1568, (1995).

[8] Ng, C.F. and Clevenson, S.A., "High-Intensity Acoustic Tests of a Thermally Stressed Plate", Journal of Aircraft, Vol. 28, No. 4, pp.275-281, (1991).

[9] Murphy, K.D., Virgin, L.N. and Rizzi, S.A., "Characterizing the Dynamic Response of a Thermally Loaded Acoustically Excited Plate", Journal of Sound and Vibrations, Vol. 196, No. 5, pp. 635-658, (1996).

[10]Locke, J. E., "Finite Element Large Deflection Random Response of Thermally Buckled Plates", Journal of Sound and Vibration, Vol. 160, No. 2, pp. 301-312, (1993).

[11]Abdel-Motagaly, K., Duan, B. and Mie, C., "Nonlinear Response of Composite Panels Under Combined Acoustic Excitation and Aerodynamic Pressure," $40^{\text {th }}$ Structures, structural Dynamics and Materials Conference, St Louis, MO, pp 1963-1972, (1999). Also AIAA Journal, Vol. 38, No. 9, pp. 1534-1542, (2000)

[12]Dhainaut, J.M., Duan, B., Mei, C., Spottswood, S.M. and Wolfe, H.F., "Nonlinear Response of Composite Panels to Random Excitations at Elevated Temperatures", $7^{\text {th }}$ International Conference on Recent Advances in Structural Dynamics, Southampton, England, pp. 769-784, (2000).

[13]Dhainaut, J.M., Gou, X. and Mei, C., "Nonlinear Random Response of Panels in an Elevated Thermal-Acoustic Environment", Journal of Aircraft, Vol. 40, No. 4, pp. 683-691, (2003).

[14]Dhainaut, J.M. and Mei, C., "Nonlinear Response and Fatigue Life of Isotropic Panels Subjected to Non-white Noise", Journal of Aircraft, Vol. 43, No. 4, pp. 975-979, (2006). 
[15] Cross, W.B., Kariotis, A.H. and Stimeler, F.J., "Nitinol Characterization Study", NASA CR-14B, (1969).

[16]Birman, V., "Review Of Mechanics Of Shape Memory Alloy Structures", Appl. Mech. Rev., Vol. 50, pp. 629-645, (1997).

[17] Jia, J. and Rogers, C.A., "Formulation Of A Mechanical Model For Composites With Embedded SMA Actuators", J. Mechanical Design, Vol. 114, pp. 670-676, (1992).

[18] Park, J.S., Kim, J.H. and Moon, S.H., "Vibration Of Thermally Post-Buckled Composite Plates Embedded With Shape Memory Alloy Fibers", Composite Structures, Vol. 63, pp. 179-188, (2004).

[19] Guo, X., "Shape Memory Alloy Applications On Control Of Thermal Buckling, Panel Flutter And Random Vibration Of Composite Panels", PhD Dissertation Old Dominion University, Mechanical Engineering Department, Norfolk, Virginia, (2005)

[20]Tawfik, M., Ro, J.J. and Mei, C., "Thermal Post-Buckling And Aeroelastic Behavior Of Shape Memory Alloy Reinforced Plates", Smart Materials and Structures, Vol. 11, 297-307, (2002).

[21]Duan, B., Tawfik, T., Goek, S., Ro, J.J. and Mei, C., "Analysis And Control Of Large Thermal Deflection Of Composite Plates Using Shape Memory Alloy", Industrial and Commercial Applications of Smart Structures, SPIE 3991, pp. 358-365, (2000).

[22] Guo, X., Przckop, A. and Mei, C., "Reduction of Random Response of Composite Plates Using Shape Memory Alloy in Thermal Environments", $45^{\text {th }}$ AIAA/ASME/ASCE/AHS/ASC Structures, structural Dynamics and Material Conference, Palm Springs, California, (2004).

[23] Xue, D.Y., "Finite Element Frequency Domain Solution Of Nonlinear Panel Flutter With Temperature Effects And Fatigue Life Analysis", PhD Dissertation, Old Dominion University, Mechanical Engineering Department, Norfolk, Virginia, (1991).

[24] Reddy, J.N., Theory and Analysis of Elastic Plates, Taylor \&Francis, (1999).

[25] Bathe, K.J., Finite Element Procedures, Prentice-Hall, Inc, Englewood Cliffs, NJ, (1996). 
Table 1 Material properties of composite matrix and SMA fiber [19]

\begin{tabular}{lll}
\hline \multicolumn{1}{c}{ Nitinol } & \multicolumn{1}{c}{ Graphite-epoxy } \\
\hline See Figs. 1 and 2 for Young's & E1 & $155\left(1-6.35 \times 10^{-4} \Delta \mathrm{T}\right) \mathrm{GPa}$ \\
modulus and recovery stresses. & E2 & $8.07\left(1-7.69 \times 10^{-4} \Delta \mathrm{T}\right) \mathrm{GPa}$ \\
G $25.6 \mathrm{GPa}$ & $\mathbf{G 1 2}$ & $4.55\left(1-1.09 \times 10^{-3} \Delta \mathrm{T}\right) \mathrm{GPa}$ \\
$\boldsymbol{\rho} \quad 6450 \mathrm{Kg} / \mathrm{m}^{3}$ & $\boldsymbol{\rho}$ & $1550 \mathrm{Kg} / \mathrm{m}^{3}$ \\
v 0.3 & $\mathbf{v}$ & 0.22 \\
$\boldsymbol{\alpha} 10.26 \times 10^{-6} /{ }^{\circ} \mathrm{C}$ & $\boldsymbol{\alpha 1}$ & $-0.07 \times 10^{-6}\left(1-0.69 \times 10^{-3} \Delta \mathrm{T}\right) /{ }^{\circ} \mathrm{C}$ \\
& $\boldsymbol{\alpha 2}$ & $30.6 \times 10^{-6}\left(1+0.28 \times 10^{-4} \Delta \mathrm{T}\right) /{ }^{\circ} \mathrm{C}$ \\
\hline
\end{tabular}

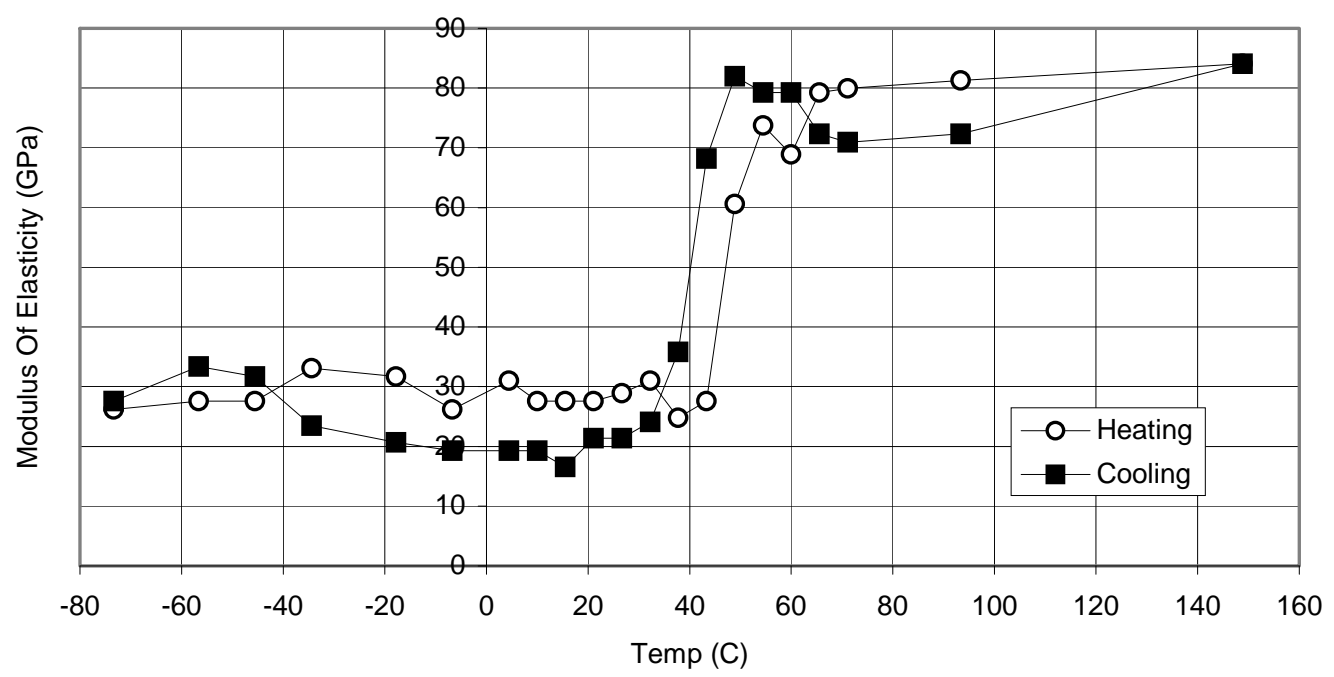

Fig.1. Variation of the SMA modulus of elasticity with temperature

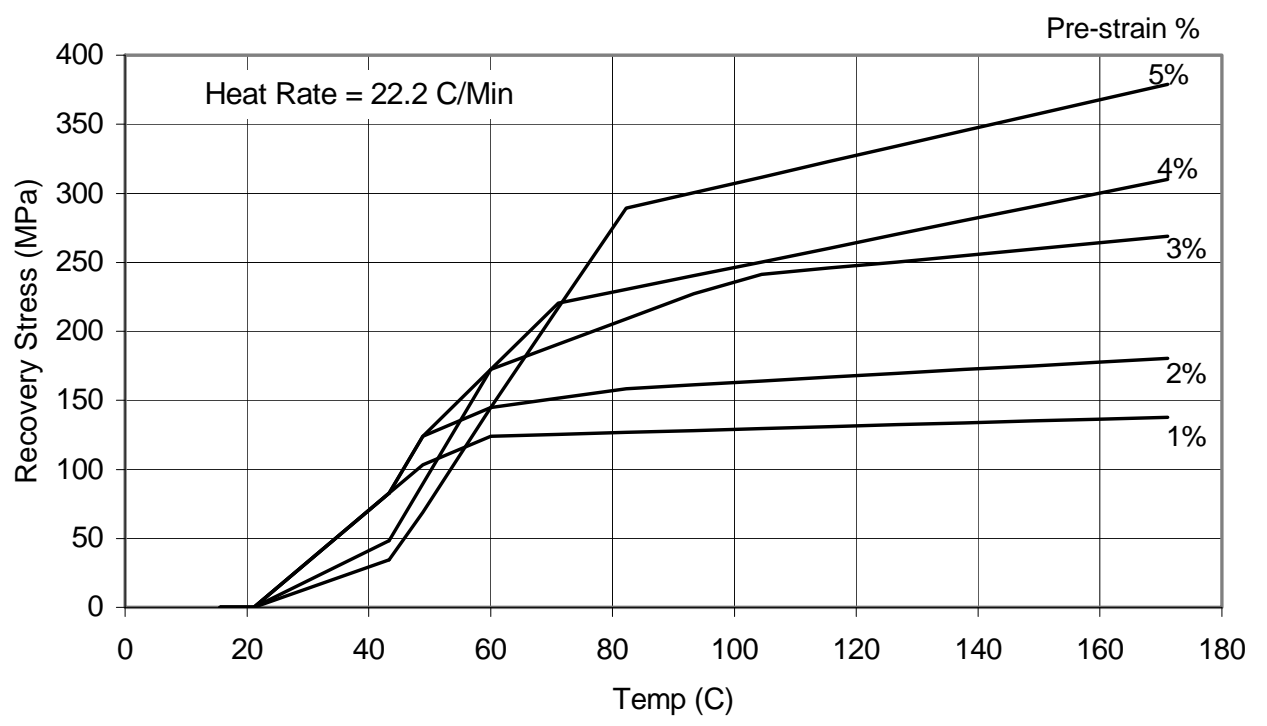

Fig.2. Recovery stresses of as a function of temperature and pre-strain 


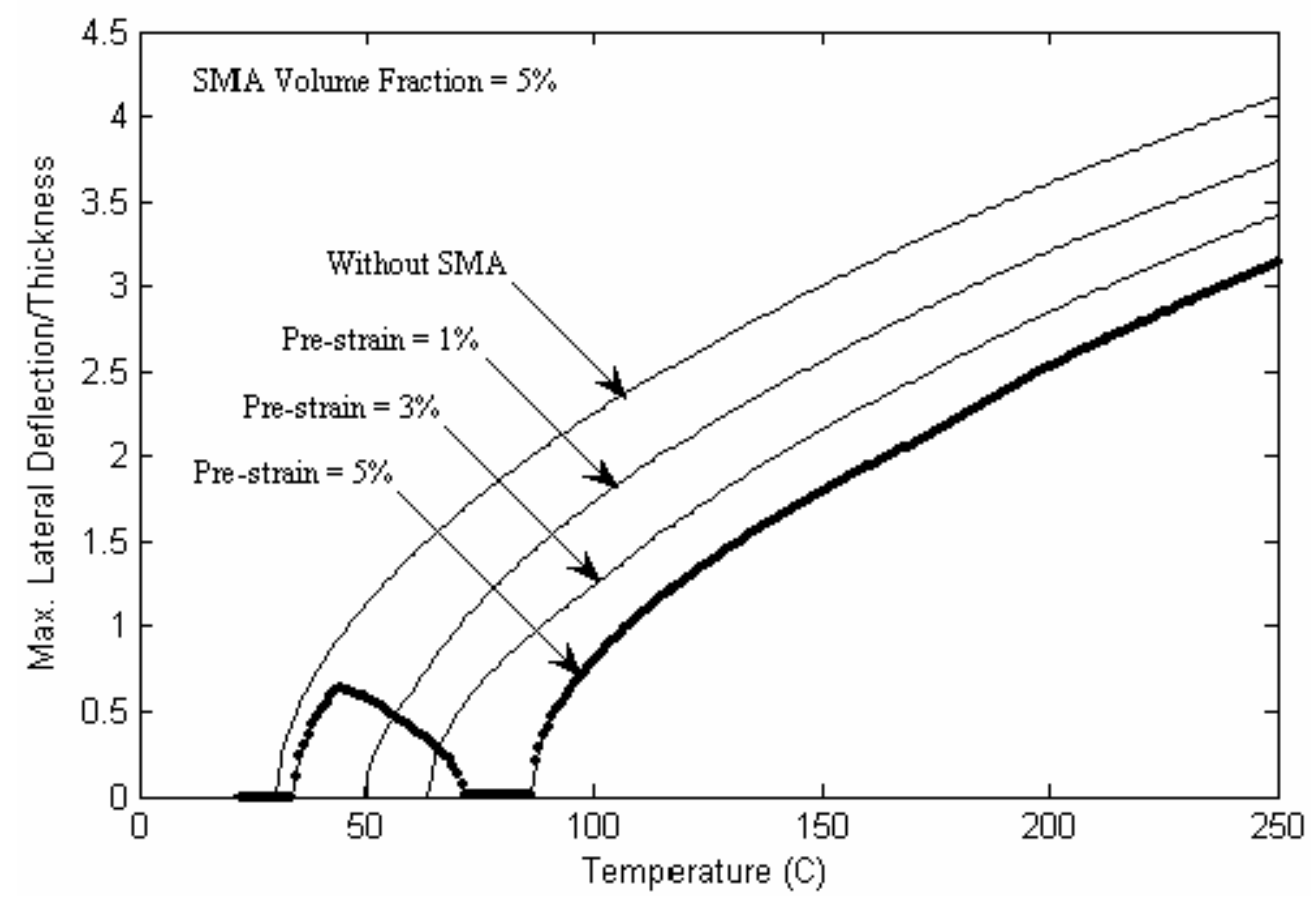

Fig.3. Maximum non-dimensional thermal deflection for a simply supported SMAHC plate with $5 \%$ volume fraction and different pre-strain values

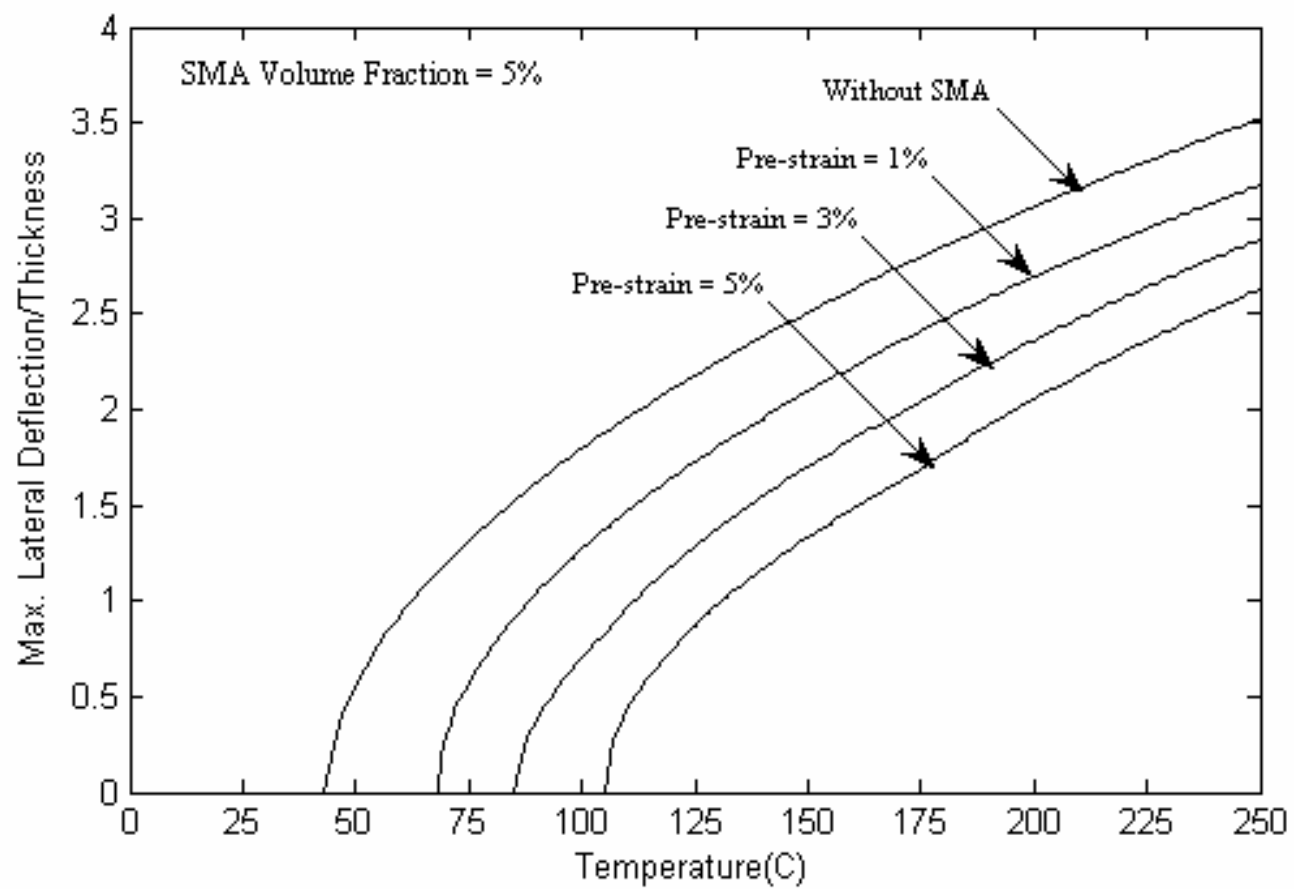

Fig.4. Maximum non-dimensional thermal deflection for a clamped SMAHC plate with $5 \%$ volume fraction and different pre-strain values 

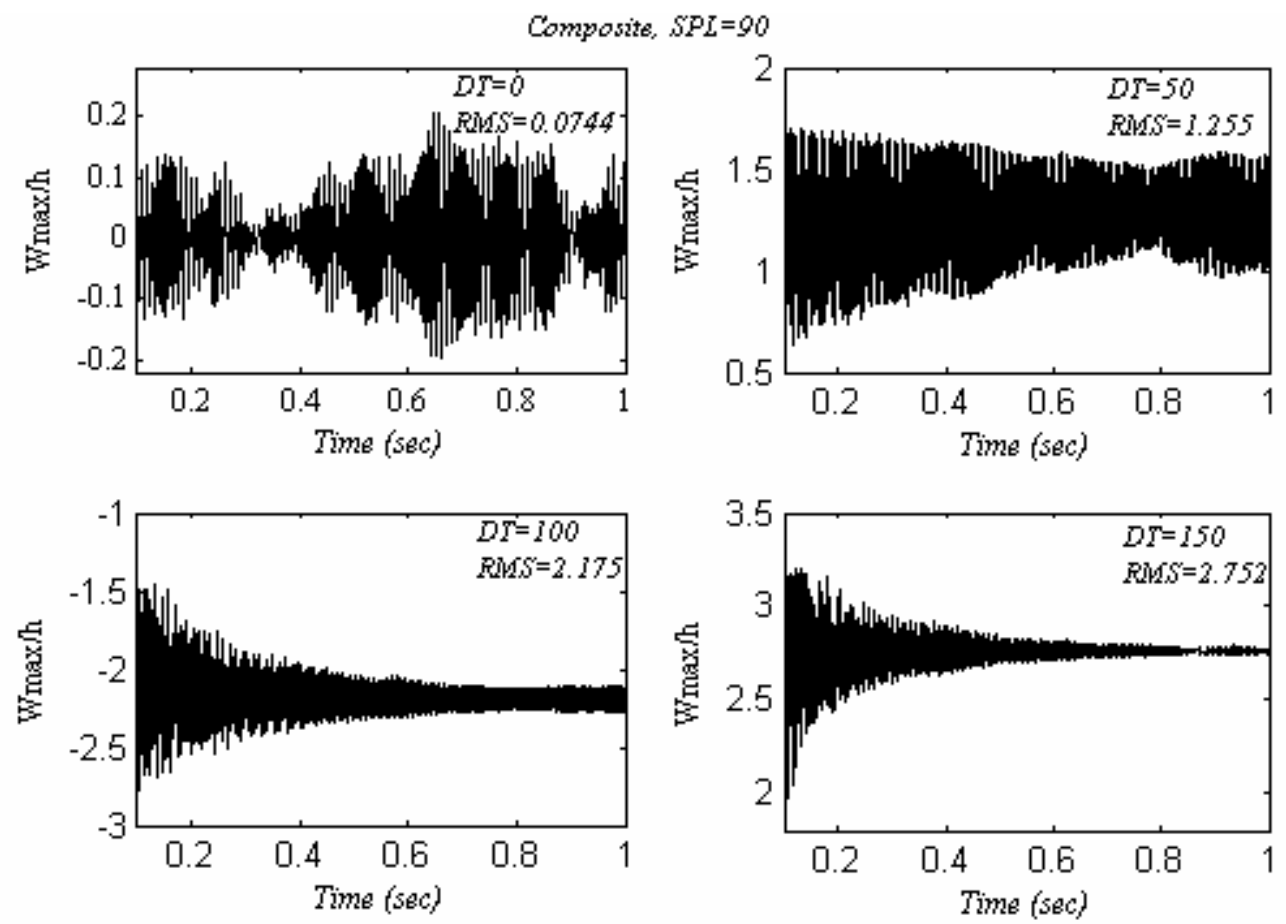

Fig.5. Random vibration response of a clamped traditional composite plate at $\mathrm{SPL}=90 \mathrm{~dB}$ and various temperature rises $\Delta \mathrm{T}$
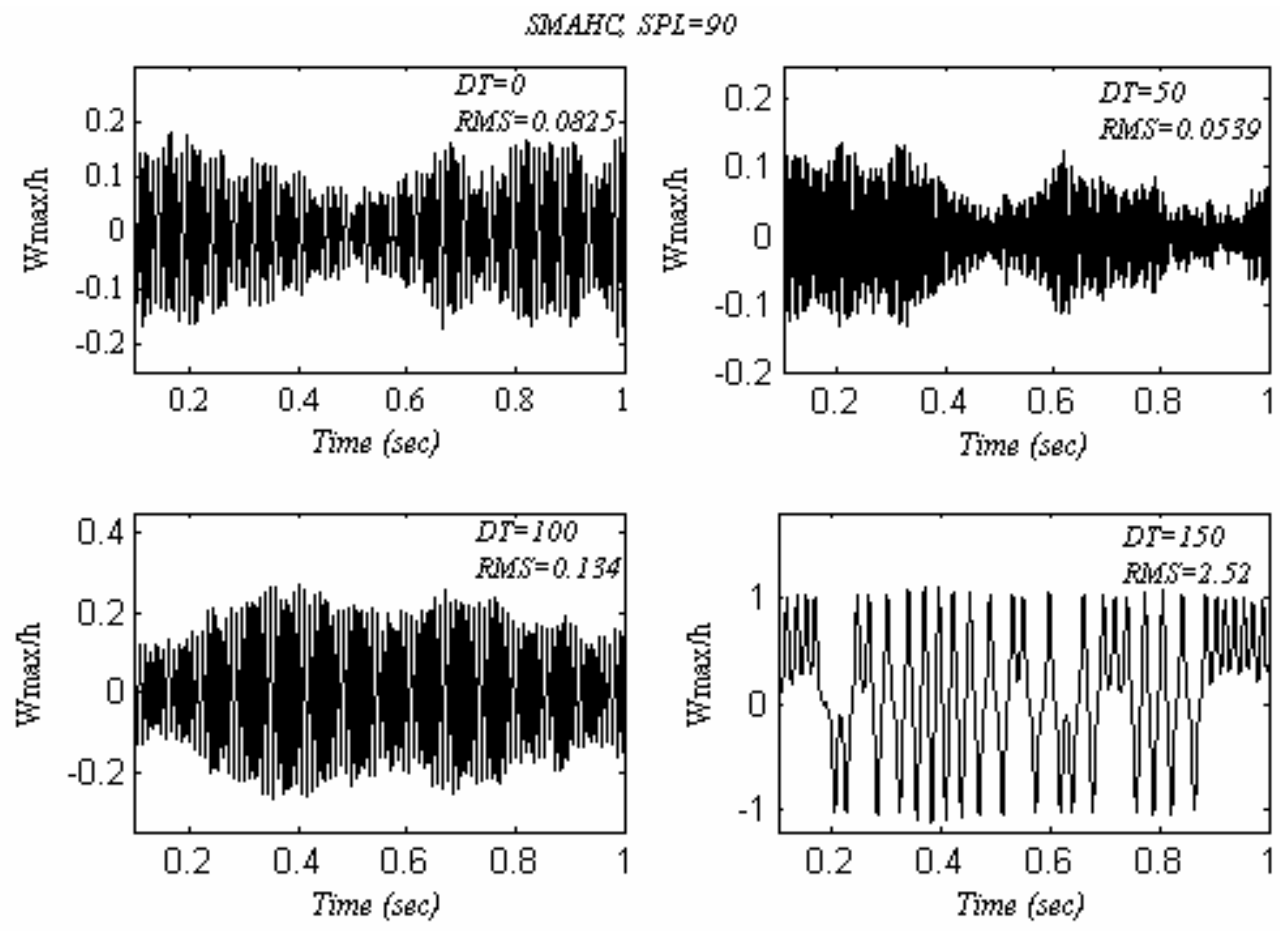

Fig.6. Random vibration response of a clamped SMAHC plate at $\mathrm{SPL}=90 \mathrm{~dB}$ and various temperature rises $\Delta \mathrm{T}$ 

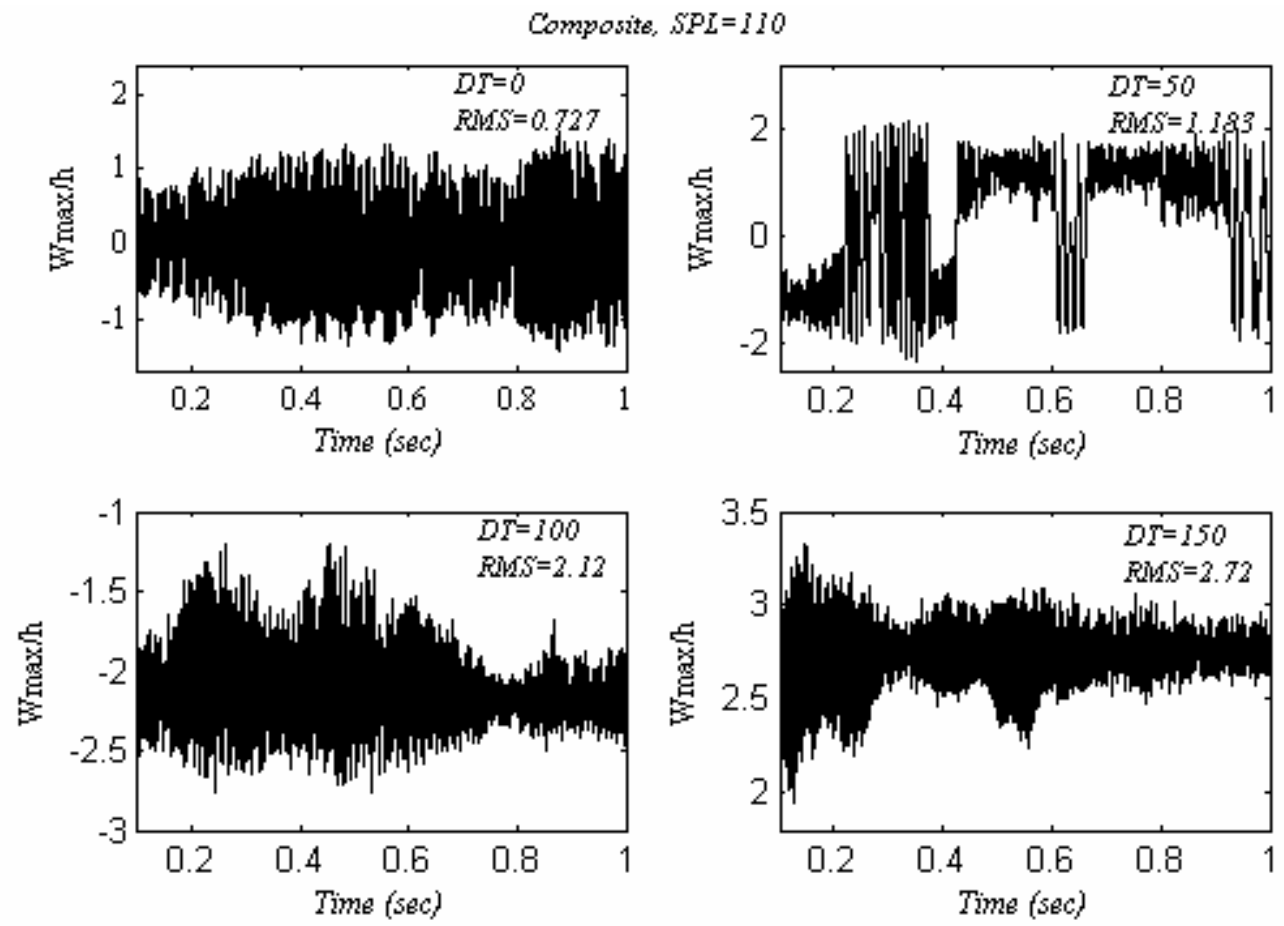

Fig.7. Random vibration response of a clamped traditional composite plate at $\mathrm{SPL}=110 \mathrm{~dB}$ and various temperature rises $\Delta \mathrm{T}$
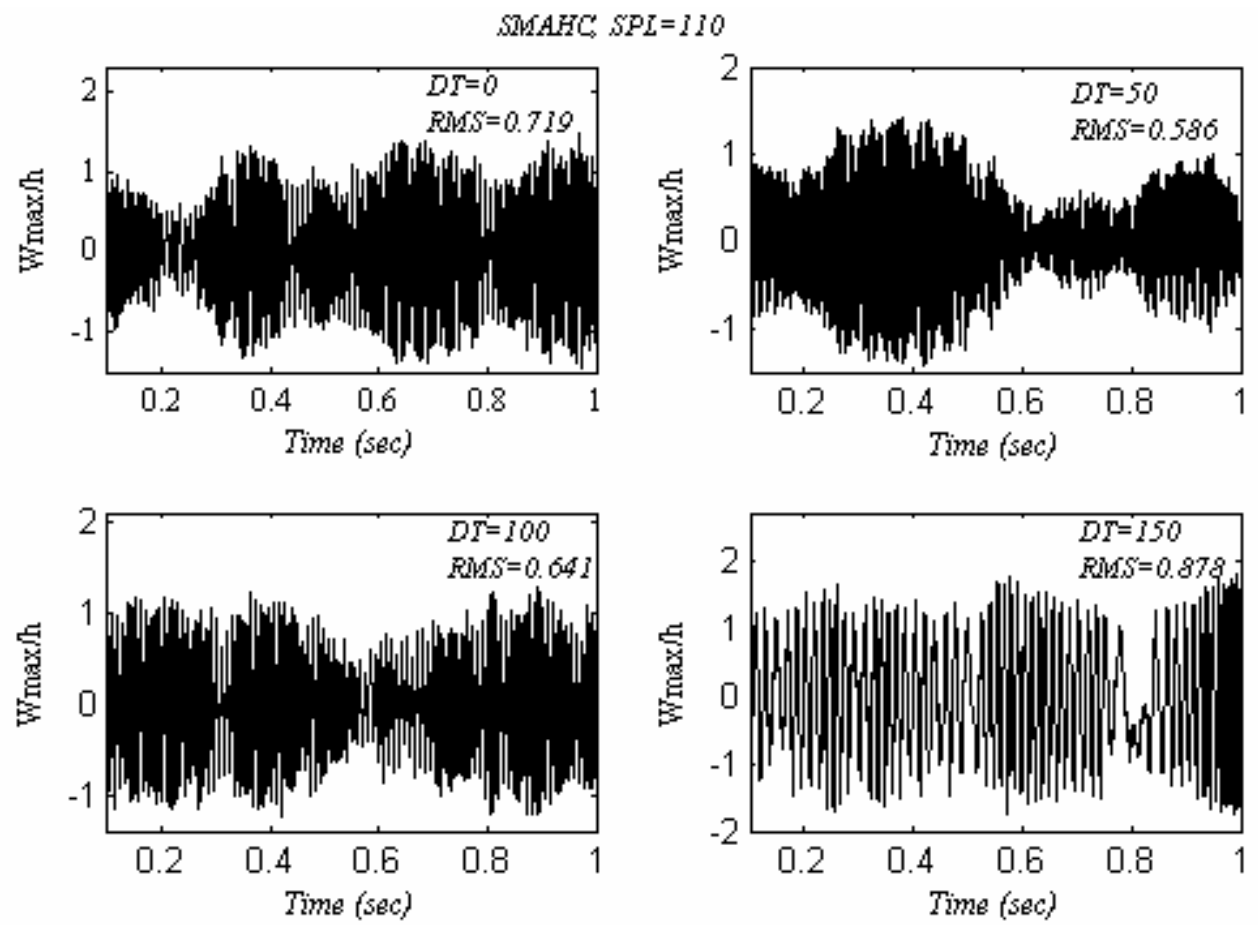

Fig.8. Random vibration response of a clamped SMAHC plate at $\mathrm{SPL}=110 \mathrm{~dB}$ and various temperature rises $\Delta \mathrm{T}$ 

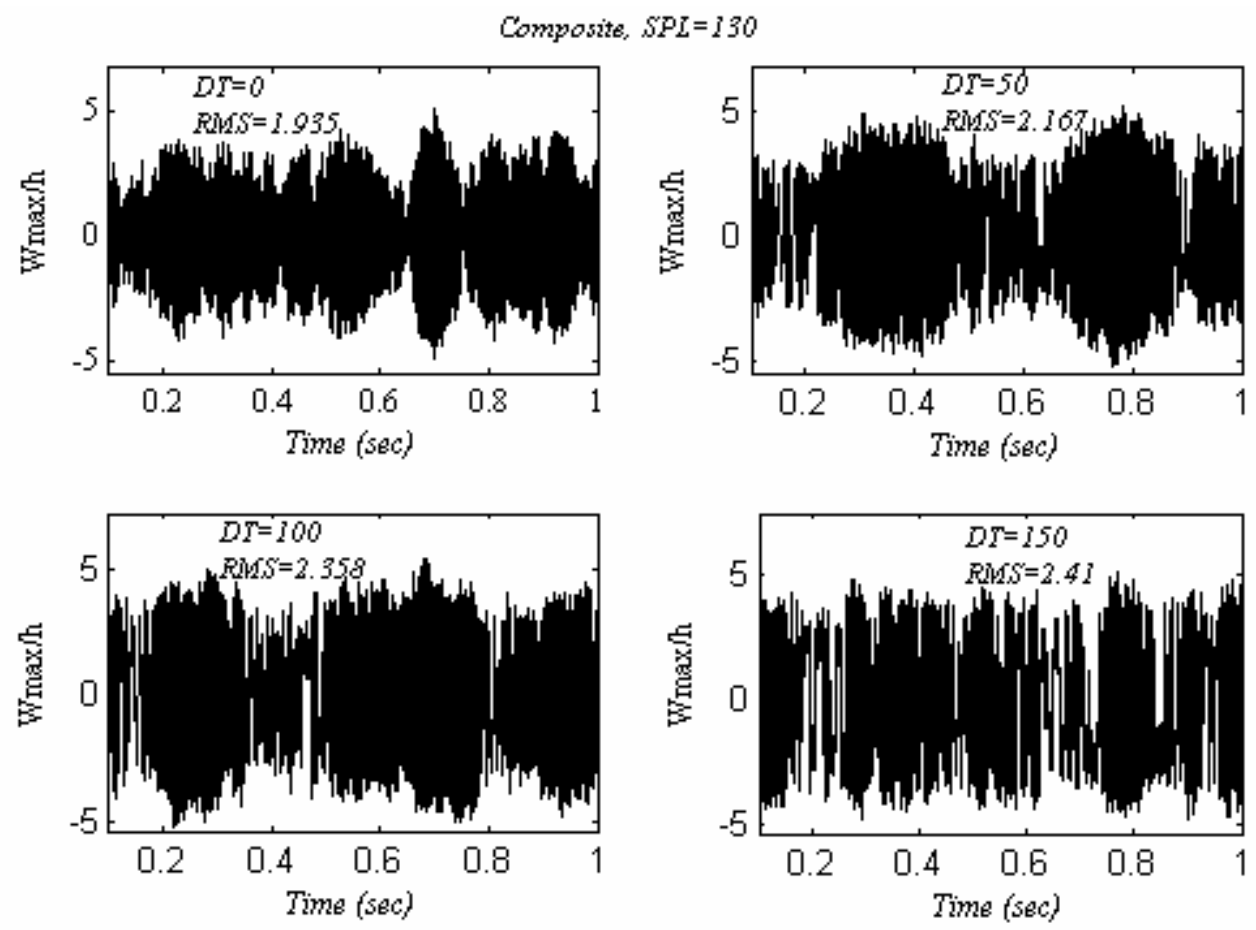

Fig.9. Random vibration response of a clamped traditional composite plate at $\mathrm{SPL}=130 \mathrm{~dB}$ and various temperature rises $\Delta \mathrm{T}$
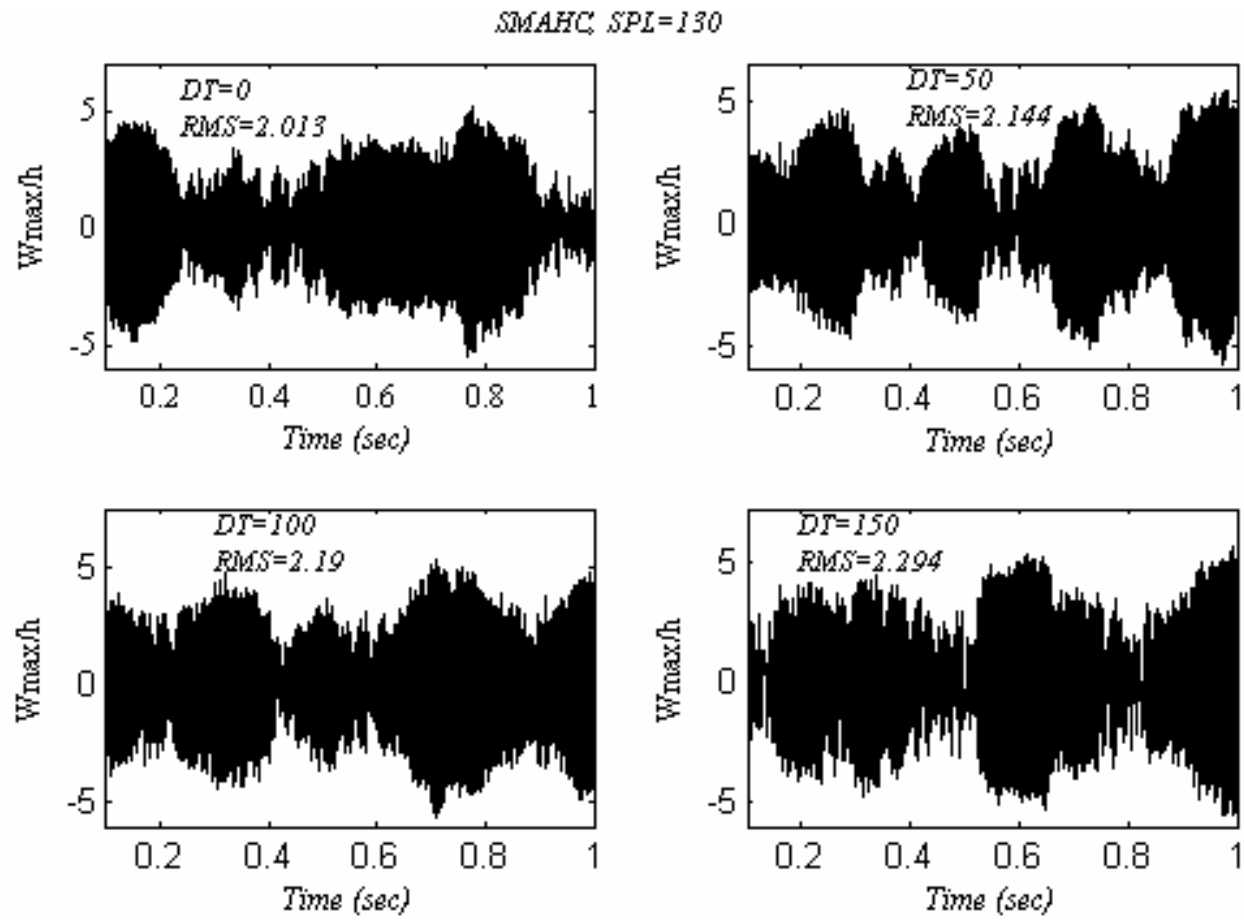

Fig.10. Random vibration response of a clamped SMAHC plate at $\mathrm{SPL}=130 \mathrm{~dB}$ and various temperature rises $\Delta \mathrm{T}$ 